activity), age, sex and MASEI score was assessed with nonlinear Spearman's rho. Significance of differences was assessed by chi-square test. The level of statistical significance of differences was set at $p$

Results: All of 35 patients with IBD presented at least one entheses alteration with a mean MASEI of 5.43 (thickness $57.1 \%$, enthesophytosis $42.8 \%$, bursitis $0 \%$, erosions $0 \%, \mathrm{PD}$ abnormalities $14.2 \%$ ) vs 3 patients of control group (enthesophytosis 14\%) (p

Conclusions: 1) IBD patients showed a significantly higher prevalence of early entheses involvement, even in the absence of clinical symptoms; 2) the entity of entheses alteration as assessed by MASEI did not correlate with type, duration and activity of IBD; 3 ) age was the only variable which significantly correlated with ultrasonographic entheses involvement.; 4) we speculate that IBD patients should undergo ultrasonography evaluation of entheses and, if any alteration, be followed up for early detection of SpA

References:

[1] Harbord M et al. J Crohns Colitis. 2016

[2] Sakellariou G et Clin Exp Rheumatol. 2014.

Disclosure of Interest: None declared

DOI: 10.1136/annrheumdis-2017-eular.4869

\section{SAT0402 FREQUENCY AND HLA PHENOTYPE OF REACTIVE ARTHRITIS, UVEITIS, AND CONJUNCTIVITIS IN JAPANESE PATIENTS WITH BLADDER CANCER FOLLOWING INTRAVESICAL BCG THERAPY: A 20-YEAR, TWO-CENTER RETROSPECTIVE STUDY}

H. Nishikawa ${ }^{1}$, Y. Taniguchi ${ }^{1}, \mathrm{~K}$. Inoue ${ }^{1}$, Y. Yoshinaga ${ }^{2}$, Y. Terada ${ }^{1} .{ }^{1}$ Koch Medical school, Nankoku; ${ }^{2}$ Kurashiki Medical center, Kurashiki, Japan

Background: Intravesical instillation of Bacillus Calmette-Guerin (iBCG) is used as an effective immunotherapy of bladder cancer. However it may have, as adverse event, a reactive arthritis $(\operatorname{Re} A)$ and the frequencies are known as about 0.5 to $1 \%$ in Western countries.

Objectives: To evaluate the frequencies and HLA phenotype of reactive arthritis $(\operatorname{Re} A)$, uveitis, conjunctivitis and other adverse events in Japanese patients with bladder cancer following iBCG therapy.

Methods: The clinical findings of Japanese patients who received iBCG $(n=555$ [250 and 305 in Kochi Medical School Hospital $\{\mathrm{KMSH}\}$ and Kurashiki Medical Center $\{K M C\}$, respectively]) for bladder cancer from March 1997 to February 2016 were retrospectively assessed, with specific attention to patients with $\operatorname{ReA}$ and conjunctivitis/uveitis. We also looked at human leukocyte antigen (HLA) phenotypes of patients with $\mathrm{ReA}$.

Results: Patient age was $73 \pm 10$ and $70 \pm 11$ years and male/female ratio was 198/52 and 240/65 in KMSH and KMC, respectively. 91/555 (16.4\%), 121/555 $(21.8 \%)$, and $196 / 555(35.3 \%)$ of all enrolled patients presented with fever, haematuria, and dysuria, respectively. Of the 555 cases, $\operatorname{ReA}$, uveitis and conjunctivitis were revealed in 11/555 (2.0\%), 4/555 (0.7\%) and 33/555 (5.9\%), respectively. The frequency and the protocol of iBCG therapy were stable over the 20 years. Notably, HLA-B27, -B35, -B39 and -B51 positivity was more frequent in ReA patients $(9.1 \%, 36.3 \%, 36.3 \%$ and $63.6 \%$, respectively) $(p<0.05)$ than in healthy subjects without $\operatorname{ReA}(0.3 \%, 8.3 \%, 4.0 \%$ and $9.1 \%$, respectively).

Conclusions: The 2.0\% ReA frequency in iBCG-treated Japanese patients exceeds that in Western countries. HLA phenotype, especially HLA-B51 and -B39 alleles in addition to -B27, may be a risk factor in iBCG-induced ReA in Japanese patients.

Disclosure of Interest: None declared

DOI: 10.1136/annrheumdis-2017-eular.1768

\section{SAT0403 ARTERIAL HYPERTENSION IN PATIENTS WITH ANKYLOSING SPONDYLITIS AND PSORIATIC ARTHRITIS - RESULTS OF 10-YEARS FOLLOW-UP}

I.Z. Gaydukova, A. Aparkina, E. Kchondkaryan, A. Rebrov. Hospital Therapy, Saratov State Medical University, Saratov, Russian Federation

Background: Spondyloarthritis (SpA) (ankylosing spondylitis (AS) and psoriatic arthritis (PsA)) are associated with increased cardiovascular risk [1]. Destabilization of arterial pressure in chronic inflammation and anti-inflammatory treatment could be one of the reasons of early cardiovascular events onset.

Objectives: The purpose of this work is evaluate the occurrence and risk of arterial hypertension $(\mathrm{AH})$ onset in patients with AS and PsA.

Methods: 663 patients were involved in the study: AS patients fulfilled mNewYork criteria (1984), PsA patients fulfilled CASPAR criteria (2006). Study included cross-sectional analyze, where 159 AS and 85 PsA patients participated, and 10-year prospective follow-up part, included 278 AS patients, 109 PsA patients. 276 patients were excluded due to lose the follow-up. In follow-up part of the study were involved SpA patients without $\mathrm{AH}$ at baseline. 182 healthy volunteers participated in the study like controls, 32 of them lost the follow-up. New cases of $\mathrm{AH}$ were registered after 4 and 10 years.

Statistics was performed in SPSS17 and GraphPadPrizm. All the results were adjusted to cardiovascular risk factors.

Results: Characteristics of the patients and controls with 10-years follow-up are presented in table 1.
Table 1. Baseline characteristics of the patients, involved in the study

\begin{tabular}{lccc}
\hline & $\mathrm{AS}, \mathrm{n}=278$ & $\mathrm{PsA}, \mathrm{n}=109$ & Controls, $\mathrm{n}=150$ \\
\hline Age, years (M \pm SD) & $40.0 \pm 11.4$ & $40.55 \pm 10.6$ & $39.0 \pm 11.2$ \\
Gender, male, $\mathrm{n}(\%)$ & $212(76.25)^{\# @}$ & $41(48.2)$ & $84(56)$ \\
Disease duration, years (M $\pm \mathrm{SD})$ & $13.7 \pm 10.03$ & $14.8 \pm 14.4$ & - \\
Obesity, $\mathrm{n}(\%)$ & $32(11.5)$ & $24(28.2)$ & $22(14.7)$ \\
Smoking, $\mathrm{n}(\%)$ & $151(54,31)^{\# @}$ & $30(35,2)$ & $40(26,7 \%)$ \\
\hline
\end{tabular}

AS, ankylosing spondylitis; PsA, psoriatic arthritis; "-", absence of data. ${ }^{\#} p<0.001$ for the difference with controls. ${ }^{\mathrm{p}}<0.001$ for the difference with PsA.

$100 \%$ of patients recieved NSAIDs, $10 \%$ - glucocorticoids (5-10 mg prednisolone), $68.8 \%$ of PsA patients recieved methotrexate (10-25 mg/week), 14.3 of AS patients - sulfasalazine (2.0-3.0 g/day)

Due to cross-sectional analyses was shown that $\mathrm{AH}$ occurred in 48.7 of $\mathrm{AS}$ and in $67.5 \%$ of PsA patients, respectively, $p=0.03$.

Numbers of new $\mathrm{AH}$ cases during follow-up are presented in table 2.

Table 2. New cases of arterial hypertension in ankylosing spondylitis, psoriatic arthritis and healthy controls after 4 and 10-years of follow-up

\begin{tabular}{|c|c|c|c|c|c|c|}
\hline & \multicolumn{2}{|c|}{ AS, $n=278$} & \multicolumn{2}{|c|}{ PsA, $n=85$} & \multicolumn{2}{|c|}{ Controls, $n=150$} \\
\hline & 4 years & 10 years & 4 years & 10 years & 4 years & 10 years \\
\hline $\mathrm{AH}$ cases, $\mathrm{n}(\%)$ & $95.0(34.1)$ & $139.0(50)^{*}$ & $59.0(69.4)$ & $61.0(71.7)^{\star}$ & $31.0(36.5)$ & $31.0(36.5)$ \\
\hline
\end{tabular}

${ }^{*} \mathrm{p}<0.0001$ for the difference with controls.

The relative risk $(\mathrm{RR})$ of $\mathrm{AH}$ onset in patients with $\mathrm{AS}$ compared to healthy individuals is 2.22 ( $95 \%$ confidential interval $(\mathrm{Cl}) 1.59-3.1)$; RR in PsA patients is $3.08(95 \% \mathrm{Cl} 2.19$ - 4.03), difference between risk of $\mathrm{AH}$ development in $\mathrm{PsA}$ and AS is significant, $p<0.0001$. Median to new AH cases in AS and PsA is $10 \pm 2.57$ years from the first SpA symptoms appearance.

Conclusions: $\mathrm{AH}$ is frequently presented in PsA patients than in AS. Risk of new $\mathrm{AH}$ onset in patients with $\mathrm{AS}$ and PSA is superior compared with the healthy individuals. The number of new cases of hypertension increases with time, and in 10 years from diagnosis half of PsA/AS patients without cardiovascular disease will be in the risk of hypertension.

References:

[1] Agca R et al. Ann Rheum Dis. 2017 Jan;76(1):17-28.

Disclosure of Interest: None declared

DOI: 10.1136/annrheumdis-2017-eular.6325

\section{SAT0404 RELATIONSHIP OF SCLEROSTIN AND DICKKOPF-1 SERUM LEVELS WITH DISEASE ACTIVITY AND INFLAMMATORY MRI LESIONS IN PATIENTS WITH SPONDYLOARTHRITIS}

I. Shynkaruk ${ }^{1}$, O. laremenko ${ }^{1}$, D. Fedkov ${ }^{1}$, K. laremenko ${ }^{2}$. ${ }^{1}$ Bogomolets National Medical University; ${ }^{2}$ Olexandrivska Kyiv City Hospital, Kyiv, Ukraine

Background: Dickkopf-1 (Dkk-1) and sclerostin (Scl) are likely to play important roles in the process of ankylosis in Spondyloarthritis (SpA) [1]. Their serum levels are associated with the formation of new syndesmophytes [2]. But the relationship between these biomarkers and disease activity including active inflammatory lesions in sacroiliac joints (SIJ) on magnetic resonance imaging (MRI) still not clear. Objectives: To estimate the relationship between the Scl and Dkk-1serum levels and active inflammatory MRI lesionsin SIJ, disease activity and functional status in SpA patients (pts).

Methods: Serum levels of Scl and Dkk-1 (pmol/l; ELISA) were measured at baseline in 79 pts with SpA. Mean age of pts (63.3\% male) was $37.5 \pm 11.3$, mean disease duration $-10.7 \pm 9.44$ yrs. Radiological sacroiliitis defined according to Kellgren grade was: $0-1.6 \%, \mathrm{I}-22 \%$, II $-49.2 \%$, III $-13.6 \%$ and IV $-13.6 \%$ Active inflammatory lesions in SIJ were evaluated with Spondyloarthritis Research Consortium of Canada (SPARCC) MRI SIJ score (0-72, n=46). Disease activity was measured by Ankylosing Spondylitis Disease Activity Score (ASDAS) using C-reactive protein (CRP), Bath Ankylosing Spondylitis Disease Activity Index (BASDAI, mm), CRP (mg/l) and erythrocyte sedimentation rate (ESR, mm/hr) Functional status estimated using Bath Ankylosing Spondylitis Functional Index (BASFI, mm). For correlation the Spearman correlation coefficient was calculated. Results: Mean value $(\mathrm{M} \pm \sigma)$ of biomarkers in all SpA pts were: $\mathrm{Scl}-19.2 \pm 11.63$ Dkk-1 $-30.7 \pm 19.5$. The mean value of indices and laboratory parameters in al SpA pts were: ASDAS-CRP - 3.01 \pm 1.09 , BASDAI - 4.36 \pm 1.88 , CRP $-20.3 \pm 33.0$, ESR $-25.8 \pm 20.7$, BASFI - 3.01 \pm 2.33 . SPARCC score was $24.6 \pm 10.9$.

$\mathrm{Scl}$ level was significantly higher in pts with lower activity by SPARCC score $(23.1 \pm 12.7)$ vs higher activity $(16.6 \pm 7.63), p=0.043$, in pts with moderate disease activity by ASDAS-CRP $(22.3 \pm 15.6)$ vs very high disease activity $(14.6 \pm 9.89)$, $\mathrm{p}=0.031$, and in women $(23.1 \pm 12.6)$ vs men $(16.9 \pm 10.5), p=0.014$. Its level didn't depend on CRP, ESR, BASDAI, BASFI and HLA B27 positivity.

$\mathrm{Scl}$ showed significantly negative correlation with BASDAI $(r=-0.381, p=0.041)$ only in women.

There was no difference in Dkk-1 serum level depending on the gender, disease activity (by ASDAS-CRP), functional status, the presence of HLA B27 and inflammatory changes in SIJ (with quartile distribution). But the correlation analysis showed significant relationship of Dkk-1 with CRP $(r=0.243, p=0.031)$ and SPARCC MRI SIJ score $(r=0.351, p=0.017)$. The strength of the correlation between Dkk-1 and CRP was slightly higher in HLA B27 positive pts $(90 \%$; $r=0.334, p=0.018$ ). 
In SpA pts with lower activity by SPARCC score significant correlation between Dkk-1 and inflammatory lesions in SIJ $(r=0.400, p=0.043)$ and a negative correlation between Dkk-1 and BASDAI $(r=-0.513, p=0.017)$ were found.

There was no correlation between Scl and Dkk-1 levels among all pts and different subgroups.

Conclusions: $\mathrm{Scl}$ level is significantly higher in pts with lower disease activity by SPARCC MRI SIJ score and ASDAS-CRP. Dkk-1 significantly positively correlates with disease activity due to CRP level and SPARCC score, but not to BASDAI. References:

[1] Xie W. Ann N Y Acad Sci. 2016 Jan; 1364: 25-31.

[2] Song I-H. Ann Rheum Dis. 2011 Jul 1; 70(7): 1257-1263.

Disclosure of Interest: None declared

DOI: 10.1136/annrheumdis-2017-eular.2430

\section{SAT0405 CLINICAL, BIOLOGICAL AND GENETIC FACTORS, PREDICTORS OF TREATMENT NONRESPONSE TO TNF INHIBITORS (TNFI), IN ANKYLOSING SPONDYLITIS (AS) AND PSORIATIC ARTHRITIS (PSA)}

J. Polo y La Borda, J. Campos, J. Sanz, J. Mulero, A. Sánchez. Reumatología, Instituto de Investigación Biomédica, Hospital Universitario Puerta de Hierro Majadahonda, Madrid, Spain

Background: TNF inhibitors (TNFi), are effective in controlling the activity of spondyloarthritis. But, there is a proportion of patients, who have to stop treatment due to its ineffectiveness or to the appearance of adverse events. In addition, these therapies imply high economic costs. To identify predictors of response, would help us to make decisions and to improve the risk/benefit ratio, in patients candidates who are candidates to initiate TNFi

Objectives: To determine clinical, biological and genetic predictors of nonresponse to treatment with TNFi in patients with AS and PsA.

Methods: We analyzed 118 patients [49 AS and 69 PsA (24 axial and peripheral involvement and 45 only peripheral)], under treatment or who were to start treatment with TNFi. Data were collected, prior to the start of the TNFi and at the last scheduled visit to the Rheumatology Service of the Hospital Puerta de Hierro, during the period 2013-2014. A clinical response was defined as the reduction $\geq 50 \%$ of the initial BASDAI, in patient with axial involvement, and if the final DAS 28 PCR was $<2.6$, in those patients with only peripheral involvement. A total of 73 men and 45 woman, mean age $53 \pm 11.2$ years, and a median duration of illness of 15 years (IQR 10-23) were included. The baseline ESR and CRP were $(10 \mathrm{~mm} / \mathrm{hr}$ IQR $5.0-27.0$ and $2 \mathrm{mg} / \mathrm{I}$ IQR $0.0-9.0)$ respectively. The mean and SD of BASDAI, DAS28 CPR and BASFI were $(6.0 \pm 1.9,3.0 \pm 0.6$ and $5.4 \pm 2.5)$ respectively. A univariate analysis was performed using a Cox proportional hazard regression model which included: Smoker status, axial pain, peripheral arthritis, sacroilitits, IBD, uveitis, psoriasis, HLA B27, VSG, PCR, BASDAI, BASFI, VGP, the number of TNFi and 45 single nucleotide polymorphism (SNPs) previously reported to be associated with response to TNFi. SNP genotyping was performed using de Sequenom MassARRAY plataform. Variables with a $P$-value $<0.1$ were included in a multivariate analysis. The discrimination capacity of the model was assessed using the Harrell $\mathrm{C}$ index. $P$-values $<0.05$ were considered statistically significant. Statistical analysis was performed with the SPSS v.17 software.

Results: The median duration of treatment was 62.9 months (IQR 40.7-96.5), the response to TNFi was $79.7 \%$ of patients, with mean and SD of BASDAI, BASFI and DAS 28 PCR $(2.7 \pm 2.2,4.2 \pm 2.8,1.5 \pm 0.6)$ respectively. The factors that increased the non-response rate, were: the group of peripheral PsA versus AS (HR 2.94, $P=0.023)$, VGP (HR 1.47, $P<0.001$ ), BASDAI (HR 1.80, $P=0.001$ ), BASFI (HR 1.52, $P=0.001)$ and the number of TNFi used $(P<0.001)$. There was a trend of significance $(P<0.10)$ for females, with a 2.13-fold lower response rate than males $(P=0.065)$. The SNPs associated were: rs4240847 of the MAPKAPK2 gene (allele A, HR 1.63, $P=0.019$ ), rs11096957 of the TLR-10 gene (T allele, HR 1.49, $P=0.011$ ), rs11541076 of the IRAK-3 (allele T, HR 1.47, $P=0.050$ ), rs916344 of the MAPK14 gene, in a recessive form, since CC alleles against CG or GG increased 10.12 times the non-response rate (HR 10,12; $P=0.027)$ and rs 11591741 of the CHUK gene (GG+GC/CC; HR 8.3, $P=0.035)$. The mutivariable analysis is shown in the following table:

Table. Multivariate analysis and factors independently associated with the nonresponse rate

\begin{tabular}{lcccc}
\hline Variable & $P$-value & $\begin{array}{l}\text { Hazard } \\
\text { ratio }\end{array}$ & \multicolumn{2}{l}{$95 \%$ IC HR } \\
Lower & Upper \\
\hline Sex (Female/Male) & 0,007 & 4,46 & 1,49 & 13,35 \\
$\begin{array}{l}\text { BASFI at the start of } \\
\text { treatment }\end{array}$ & 0.000 & 1,75 & 1,31 & 2,35 \\
rs11591741 (GG/GC 0 CC) & 0,022 & 3,83 & 1,21 & 12,12 \\
\hline Discriminatory capacity of the model, Harrell Index C 0.92 &
\end{tabular}

Conclusions: Female gender, basal BASFI elevated and SNP rs11591741 (GG) of $C H U C K$ gene were identified as predictors of nonresponse to TNFi treatment in these patients.

Acknowledgements: This work has been supported by FIS (PI11/00400)

Disclosure of Interest: None declared

DOI: 10.1136/annrheumdis-2017-eular.3142

\section{SAT0406 PREVALENCE OF VERTEBRAL FRACTURES IN AXIAL SPONDYLOARTHRITIS. A SYSTEMATIC REVIEW OF OBSERVATIONAL STUDIES}

J.C. Nieto-González ${ }^{1}$, R. Cubero ${ }^{2}$, S. Castañeda ${ }^{3}$, J. Ramírez ${ }^{4}$, L. Carmona ${ }^{2}$. ${ }^{1}$ Rheumatology, Hospital G.U. Gregorio Marañón; ${ }^{2}$ Statistics, Instituto de Salud Musculoesquelética; ${ }^{3}$ Rheumatology, Hospital la Princesa, Madrid;

${ }^{4}$ Rheumatology, Hospital Clinic, Barcelona, Spain

Background: Some studies have described a higher rate of osteoporosis in axial spondyloarthritis (AxSpA). However, there are still some doubts about whether vertebral fractures (VF) should be a concern in AxSpA patients

Objectives: To evaluate the prevalence and incidence of VF in AxSpA

Methods: A systematic review was performed in Medline, Embase and Cochrane Library databases limited to studies published from Jan/2006 to Dec/2015) in Spanish, Italian and English. Search strategy combined synomyms of AxSpA, fractures, plus a filter study type. We selected cross-sectional or longitudinal studies estimating the prevalence and/or incidence of VF in adult AXSpA patients Results: The search retrieved 3944 references which after screening by title and abstract ended in 90 studies to study in depth. Finally, 12 estudies were included. The majority of the studies evaluated the VF prevalence, and only 2 studies evaluated the incidence of VF. Prevalence estimates depended on VF definitions, varying between $4.1 \%$ (clinically diagnosed VF) and $32.4 \%$ (morphometric fracture by Genant definition). Table 1 shows all studies included and their data

Conclusions: The published studies that focus on VF in AxSpA are very heterogeneous, but in general showed a slight increase in the VF prevalence. More studies are need focused on VF incidence in AxSpA

Acknowledgements: Funding: This Project was funded by Merck Sharp \& Dohme Spain. Merck Sharp \& Dohme did not influenced neither the development of the review nor the confection of the abstract.

Disclosure of Interest: None declared

DOI: 10.1136/annrheumdis-2017-eular.3574

\begin{tabular}{|c|c|c|c|c|c|c|c|}
\hline Author, year & Country/ies & Design & $\mathrm{N}$ & Population & Primary objective & Vertebral fracture & Incidence or Prevalence \\
\hline Kang 2014 & South Korea & Prospective & 298 & AS & VF incidence & Clinically diagnosed VF & $\begin{array}{l}4.1 \% \text { at } 2 \text { years } \\
13.6 \% \text { at } 4 \text { years }\end{array}$ \\
\hline Robinson 2013 & Sweden & Cross-sectional (survey) & 17764 & AS & VF prevalence & Clinically diagnosed VF & $4.1 \%$ \\
\hline Feldtkeller, 2006 & $\begin{array}{l}\text { Germany } \\
\text { Holand } \\
\text { Belgium }\end{array}$ & Retrospective survey & 1080 & AS & VF prevalence and incidence & Clinically diagnosed VF & $5.7 \%(4.3 \%$ after trauma $)$ \\
\hline Jun 2006 & South Korea & Cross-sectional & 68 & AS & VF prevalence & Genant & $16.2 \%$ \\
\hline Klingberg 2013 & Sweden & Cross-sectional & 69 & AS & VF prevalence & Genant & $12 \%$ \\
\hline Montala 2011 & Spain & Cross-sectional & 176 & AS & VF prevalence & Genant & $32.4 \%(25.5-39.3 \%)$ \\
\hline Rossini 2015 & Italy & Cross-sectional & $\begin{array}{c}71 \text { AS } \\
71 \text { healthy }\end{array}$ & AS & VF and relation with bone remodeling & Genant & $29 \%$ \\
\hline Van der Weijden 2012 & Holand & Cross-sectional & $\begin{array}{c}113 \text { AxSpa } \\
80 \text { AS }\end{array}$ & EspAx & VF prevalence & Genant & $15 \%$ \\
\hline Mitra 2000 & England & Cross-sectional & $\begin{array}{c}66 \text { AS } \\
39 \text { healthy }\end{array}$ & AS (Males) & VF prevalence and relation with BMD & Mc Closkey & $16.7 \%$ \\
\hline Mehmet 2007 & Turkey & Cross-sectional & $\begin{array}{c}59 \text { AS } \\
40 \text { healthy }\end{array}$ & AS & VF prevalence & Tourissot & $31 \%$ \\
\hline Ulu 2013 & Turkey & Cross-sectional & $\begin{array}{c}86 \text { AS } \\
50 \text { Healthy }\end{array}$ & AS & VF prevalence & Tourissot & $28 \%$ \\
\hline Ulu 2014 & Turkey & $\begin{array}{l}\text { Cross-sectional } \\
\text { Case y controls }\end{array}$ & 59 & AS & VF prevalence & Tourissot & $32.5 \%$ \\
\hline
\end{tabular}

